\title{
ANALISIS EFISIENSI TENAGA KERJA USAHATANI PADI ( Oryza sativa L ) PADA LAHAN KERING DENGAN CARA TANAM JAJAR LEGOWO DI DESA SUNGAI LURUS
}

\author{
(Labour Efficiency Analysis Of Rice (Oryza sativa L) Farm On dry Land with how to plant \\ Jajar Legowo in Sungai Lurus Villages)
}

\section{Yayuk Minta Wahyuningsih, dan Baparki}

Program Studi Agribisnis Fakulitas Pertanian Universitas Achmad Yani Banjarmasin Jl. A. Yani KM 33 Banjarbaru

Email :Yayukmintawahyuningsih@gmail.com; baparki_ahmad@yahoo.co.id

Article Submitted : 15-09-2020

Article Accepted :02-10-2020

\begin{abstract}
This research was conducted to know,level of labour efficiency of rice farm effort.Survey with observation technique was used as a method,where farmer follow the example of taken at random modestly as much 29 farmer. Result of research obtained by storey,level of productivity equal to $2.081,44 \mathrm{~kg} / \mathrm{ha}$ and acceptance equal to $\mathrm{Rp} 16.651 .538,46 / \mathrm{ha}$. Distribution of external labour family( TKLK) 88,73 \% and family labour ( TKDK) $11,27 \%$ from totalizeing the labour effusing. while allocation for labour cost equal to $75,85 \%$ to total cost representing group of biggest expense rice. Count efficiency of labour from facet of labour productivity obtained value 17,18 kg/HKO,from facet labour Productivity Indect Obtained Rp 84.046,71 /HKO and from wide facet equal to $82,54 \mathrm{~m} 2 / \mathrm{HKO}$.
\end{abstract}

Keywords: Rice,Labour Efficiency,Index Labour Productivity, Total Cost and Revenue

\section{PENDAHULUAN}

Semakin meningkatnya alih fungsi lahan,disinyalir peluang penggunaan lahan sawah untuk usaha pertanian makin hari makin menyempit sehingga pengalihan usaha ke lahan kering makin terasa diperlukan. Lahan kering merupakan salah satu potensi yang belum dimanfaatkan secara optimal untuk usaha pertanian. Salah satu peluang usahatani yang dapat dikembangkan pada lahan kering adalah padi gogo (Prayitno; 2005).

Pada usahatani lahan kering salah satu tantangannya yaitu bagaimana upaya ataupun cara yang harus dilakukan untuk mendapatkan hasil produksi padi yang tinggi.Namun untuk mewujudkan upaya tersebut masih terkendala karena jika diperhatikan masih banyak petani yang belum mau melaksanakan anjuran
sepenuhnya.Sebagai contoh dalam hal ssitem tanam masih banyak petani yang bertanam tanpa jarak tanam yang beraturan atau cara tanam tabur benih langsung.

(Prosiding Seminar Nasional,2006).

Dalam upaya meningkatkan produktivitas padi, baik dengan intensifikasi maupun ekstensifikasi selalu dihadapkan dengan berbagai masalah,terutama dalam penggunaan berbagai sumber input dan faktor produksi yang penguasaannya selalu terbatas pada petani kecil.Salah satunya faktor tenaga kerja,dimana distribusi tenaga kerja dalam usahatani tidak merata sepanjang tahun. Yang perlu diperhatikan produktivitas kerja yang biasa disebut prestasi kerja,dimana efisiensi tenaga kerja disebut pula produktivitas tenaga kerja yang dapat diukur dengan memperhatikan penerimaan,luas lahan dan luas usaha. 
Efisiensi Tenaga Kerja merupakan satuan kerja untuk mengukur jumlah pekerjaan produktif yang berhasil diselasaikan oleh seorang untuk mencapai tujuan dengan menggunakan sumber-sumber seminimal mungkin. Sedangkan satuan yang sering dipakai dalam perhitungan kebutuhan tenaga kerja adalah HKO (Hari kerja orang).

Di desa Sungai Lurus Kecamatan Sambung Makmur merupakan salah satu Desa yang berada di Kabupaten Banjar yang mayoritas penduduknya berusaha dibidang pertanian terutama padi lahan kering. Pada kegiatan budidaya padi lahan kering masih bersifat tradisional dan cara bertanamnya sebagian besar masih banayak menggunakan sistem tabur secara langsung dibandingkan dengan menggunakan pengaturan jarak tanam atau sistem cara tanam Jajar legowo.

Namun beberapa tahun terakhir di Desa Sungai lurus, petani padi lahan kering banyak yang berpindah cara tanam dengan menggunakan jarak tanam atau dengan sistem jajar legowo dengan alasan produksi yang dihasilkan lebih tinggi dibandingkan dengan cara tanam tabur benih secara langsung.

Usahatani padi di Lahan kering merupakan tanaman yang sudah lama dibudidayakan di Desa Sungai Lurus Kecamatan Sambung Makmur dengan manajemen tenaga kerja sederhana tapi mempunyai potensi besar untuk dikembangkan,sehingga peneliti mengamati secara tehnis dan ekonomis dalam efisiensi tenaga kerja pada usahatani padi lahan kering.

\section{METODE PENELITIAN}

Metode yang digunakan dalam pelaksanaan penelitian ini adalah :Wawancara dilakukan kepada responden dan Observasi yaitu dengan melakukan pengamatan secara langsung kepetani yang berlokasi di desa Sungai Lurus Kecamatan Sambung Makmur dan Tehnik pengambilan sampel dilakukan secara Purposive
Sampling yaitu dipilih petani padi lahan kering varietas Situbagendit, dengan cara sistem jajar legowo sebanyak 290 orang.Pengambilan sampel petani dilakukan secara sample,random sampling yaitu diambil $10 \%$ dari jumlah populasi senhingga didapat 29 petani yang menggunakan sistem jajar legowo.

Data yang digunakan dalam penelitian ini adalah data primer dan data sekunder baik data yang bersifat kualitatif maupun kuantitatif. Data primer diperoleh melalui wawancara meliputi keadaan umum petani, manajemen yang diterapkan dan kegiatan usahatani yang dijalankan. Data sekunder diperoleh dari Dinas Pertanian serta literatur-literatur dan bahan pustaka lain yang relevan.

\section{Analisis Data}

Menurut Syarifuddin A. kasim (1995;15), untuk mengetahui penerimaan secara matematis dapat ditulis sebagai berikut:

$$
\begin{array}{cc} 
& \mathrm{TR}=\mathrm{P} \times \mathrm{Q} \\
\mathrm{TR} \quad & =\text { Total Revenue / Penerimaan total } \\
& (\mathrm{Rp}) \\
\mathrm{P} \quad= & \text { Price / Harga (Rp/kg) } \\
\mathrm{Q} \quad \quad=\text { Quantity / produksi }(\mathrm{kg}) \\
& \text { Untuk menghitung Distribusi }
\end{array}
$$

penggunaan Tenaga Kerja dalam usahatani padi lahan kering di daerah tersebut dengan rumus sebagai berikut:

$$
\mathrm{DL}=\mathrm{LC} / \mathrm{TC} \times 100 \%
$$

$\mathrm{DL}=$ Distribusi of labour Cost (Distribusi

Biaya Tenaga Kerja)

LC $=$ Labour Cost $($ Biaya Tenga Kerja $)$

(Rp)

Efisiensi Tenaga Kerja atau Produktivitas tenaga kerja dapat diukur dengan memperhatikan jumlah produksi, penerimaan per hari dan luas lahan usaha, sedangkan efisiensi tenaga kerja dalam usahatani padi menggunakan rumus :

$$
\mathrm{Eq}=\sum \mathrm{P} / \mathrm{ZL} \text { atau } \mathrm{IP}=\mathrm{TR} / \sum \mathrm{L}
$$

$\mathrm{Eq}=$ Eficyency $/$ Efisiensi tingkat produksi $(\mathrm{kg})$

IP = Index Produktivitas $(\mathrm{kg} / \mathrm{ha})$

$\mathrm{L}=$ Labour/Tenaga Kerja $(\mathrm{HKO} / \mathrm{ha})$ 
Kriteria : Jika IP lebih besar dari tingkat upah berarti tenaga kerja produktif, jika IP lebih kecil atau sama dengan tingkat upah berarti tidak produktif.

\section{HASIL PEMBAHASAN}

Dari hasil pengamatan diketahui ratarata luas lahan usahatani padi lahan kering varietas Situbagendit dengan cara tanam jajar legowo sebesar 1,04 ha dari 29 petani responden. Adapun komponen biaya dianalisis secara tabulasi meliputi biaya eksplisit dan biaya implisit.

\section{Biaya Sarana Produksi}

Biaya sarana produksi yang dikeluarkan pada usahatani padi meliputi biaya benih,pupuk dan obat-obatan. Besarnya biaya sarana produksi rata-rata sebesar Rp 2.161.886/petani.Biaya benih yang dikeluarkan rata-rata sebesar 26,5 $\mathrm{kg} /$ petani.Biaya terbesar dalam penggunaan input adalah biaya pupuk kandang.Untuk lebih jelasnya dapat dilihat pada Tabel 1 .

Tabel 1. Biaya Rata-rata Sarana Produksi

\begin{tabular}{clccr}
\hline No & Jenis Sarana Produksi & Kebutuhan & Harga( Rp) & $\begin{array}{c}\text { TOTAL } \\
(\mathrm{Rp})\end{array}$ \\
\hline 1 & Benih & $26,5 \mathrm{~kg}$ & 20.000 & 530.000 \\
2 & Urea & $155,2 \mathrm{zak}$ & 110.000 & 341.379 \\
3 & SP36 & $105,2 \mathrm{zak}$ & 120.000 & 252.414 \\
4 & Ponska & $53,4 \mathrm{zak}$ & 125.000 & 133.621 \\
5 & Marshal & $8,5 \mathrm{~kg}$ & 22.000 & 178.750 \\
6 & Furadan & $9,1 \mathrm{~kg}$ & 30.000 & 273.000 \\
7 & Spontan & $850 \mathrm{ml}$ & 42.000 & 89.250 \\
8 & Matador & $240 \mathrm{ml}$ & 19.000 & 57.000 \\
9 & Lindomin & $844,4 \mathrm{ml}$ & 29.000 & 62.028 \\
10 & Ronund up & 53.0001 & 55.000 & 244.444 \\
\hline & & \multicolumn{3}{c}{ Total } \\
\end{tabular}

Sumber : Pengolahan data primer 2020

Dari Tabel 1 terlihat bahwa biaya produksi tertinggi adalah benih yaitu sebesar Rp.530.000,. dan biaya terendah adalah biaya Matador sebesar Rp. 57.000.. Dalam pelaksanaan usahatani padi lahan kering rata-rata biaya yang harus dikeluarkan sebesar Rp. 2.161.886,.

\section{Biaya Alat dan Perlengkapan}

Dalam Usahatani padi,alat dan perlengkapan yang digunakan masih sederhana,tetapi diperhitungkan berdasarkan nilai susutnya karena alat tidak habis dalam satu kali musim tanam. Perhitungan nilai penyusutan alat dan perlengkapan ini berdasarkan metode garis lurus (Straight line Method).

Tabel 2. Biaya rata-rata penyusutan alat dan Perlengkapan

\begin{tabular}{clc}
\hline No. & \multicolumn{1}{c}{ Jenis Alat dan Perlengkapan } & Biaya (Rp) \\
\hline 1 & Parang & 6.892 \\
2 & Arit & 5.429 \\
3 & Ember & 14.857 \\
4 & Sprayer & 18.159 \\
\hline & Total & 45.335 \\
\hline
\end{tabular}

Sumber : Pengolahan data primer 2020 
Adapun rata-rata alat dan perlengkapan yang digunakan pada usahatani padi di Desa Sungai Lurus sebesar Rp 41.889,.Untuk lebih jelasnya dapat dilihat pada Tabel 2.

Dari Tabel 2 terlihat bahwa biaya rata-rata penyusutan alat dan perlengkapan tertinggi adalah biaya Sprayer yang dikeluarkan yaitu sebesar Rp. 18.158,. sedangkan Arit merupakan biaya rata-rata yang terkecil yaitu sebesar Rp. 5.429,

\section{Biaya Rata-rata Tenaga Kerja}

Kebutuhan dan distribusi tenaga kerja berdasarkan proses produksi pada usahatni padi dan sumber tenaga kerja berasal dari dalam dan luar keluarga. Biaya yang diperhitungkan petani untuk membayar tenaga kerja dalam keluarga ini sebagai pendapatan keluarga petani itu sendiri.Sedangkan penggunaan tenaga kerja diluar keluarga sebagai biaya eksplisit. Satuan yang dipakai dalam perhitungan kebutuhan tenaga kerja adalah HKO (selama 8 jam/HKO).

Dari hasil pengamatan secara keseluruhan,kegiatan usahatani padi di Desa Sungai Lurus.Distribusi tenaga kerja luar keluarga(TKLK) sebesar $88,73 \%$ dan tenaga kerja dalam keluarga ( TKDK) sebesar 11,27 \% dari seluruh total tenaga kerja yang tercurah,untuk lebih jelasnya dapat dilihat pada tabel 3 di bawah ini.

Tabel 3 Distribusi dan Biaya Rata-rata Tenaga Kerja

\begin{tabular}{lccc}
\hline TKLK & Jumlah TK(HKO) & Biaya TK (Rp) & $\begin{array}{c}\text { \% thd Total Biaya } \\
\text { Keseluruhan }\end{array}$ \\
\hline Pengolahan tanah & $15,1(11,98 \%)$ & 1.062 .070 & $9,46 \%$ \\
Penanaman & $15,0(11,91 \%)$ & 1.050 .000 & $9,35 \%$ \\
Penyiangan & $28,9(22,94 \%)$ & 1.717 .794 & $15,29 \%$ \\
Panen & $52,8(41,90 \%)$ & 3.694 .450 & $32,91 \%$ \\
Jumlah TKLK & $11,8(88,73 \%)$ & 7.524 .314 & $67,01 \%$ \\
TKDK(Pemupukan) & $14,2(11,27 \%)$ & 992.070 & $8,84 \%$ \\
Total Biaya TK & $126(100 \%)$ & 8.516 .384 & $75,85 \%$ \\
\hline
\end{tabular}

Total Biaya Usahatani

$11.227 .491,57$

Padi

Sumber : Pengolahan data primer 2020

Besarnya biaya untuk masing-masing jenis kegiatan sama,yaitu untuk kegiatan pengolahan lahan,penanaman ,pemupukan dan panen sebesar Rp 70.000,./HKO. Dari Tabel 3 tersebut alokasi biaya terbesarr pada kegiatan Panen sebesar Rp 3.694.450,.

(52,8 HKO), hal ini disebabkan pada kegiatan ini sebagian besar menggunakan Tenaga Kerja dari luar. Diketahui alokasi biaya untuk curahan Tenaga Kerja sebesar $75,85 \%$ yaitu terdiri dari TKLK sebesar $67,01 \%$ dan TKDK sebesar 8,84\% terhadap biaya total yang dikeluarkan petani
padi.Adapun Produktivitas Tenaga Kerja yaitu $126 \mathrm{HKO} / 1,04$ ha sebesar 121,15 $\mathrm{HKO} / \mathrm{ha}$.

\section{Biaya Total Usahatani Padi}

Penggunaan modal dalam usahatani padi dapat dibagi dalam biaya eksplisit yaitu biaya sarana produksi,penyusutan alat, Tenaga kerja luar keluarga dan biaya implisit yaitu Tenaga kerja Dalam Keluarga dan modal. Alokasi biaya tersebut dapat dilihat pada Tabel 4. 
Tabel 4. Rata-rata Biaya Usahatani Padi

\begin{tabular}{lrc}
\hline Jenis Biaya & Biaya ( Rp) & Persentase ( \% ) \\
\hline Saran Produksi & 2.161 .886 & 19,26 \\
Penyusutan alat & 45.335 & 0,40 \\
Tenaga Kerja & 8.516 .384 & 75,85 \\
Pajak Lahan & $7.156,6$ & 0,064 \\
Bunga Modal & $496.729,97$ & 4,42 \\
\hline Jumlah & $11.227 .491,57$ & 100 \\
\hline
\end{tabular}

Dari Tabel 4 diketahui biaya yang terbesar pada penggunaan Tenaga kerja yaitu sebesar $\operatorname{Rp} 8.516 .384$, $(75,85 \%)$ dari seluruh modal yang tersedia.Hal ini disebabkan tanaman semusim yang sifatnya komersial dari segi ekonomis akan membutuhkan tenaga kerja yang lebih banyak dari usahatani yang tanaman tahunan yang sifatnya subsisten.

\section{Penerimaan Usahatani Padi}

Hasil Pengamatan secara tehnis usahatani padi di Desa Sungai Lurus diperoleh tingkat produksi rata-rata sebesar $2.164,7 \mathrm{~kg}$ (2,16 ton) dengan rata-rata luas lahan 1,04 ha atau tingkat produktivitas $2.081,44 \mathrm{~kg} / \mathrm{ha}(2,081 \mathrm{ton} / \mathrm{ha})$.Dari hasil perhitungan rata-rata penerimaan padi gogo selama satu kali musim tanam sebesar Rp 17.317.600,./1,04 ha atau $\mathrm{Rp}$ 16.651.538,46/ha,. dengan rata-rata harga padi $\mathrm{Rp} 8.000$,

\section{Efisiensi Tenaga Kerja}

Perhitungan tingkat efisiensi tenaga kerja atau produktivitas tenaga kerja pada usahatani padi di Desa Sungai Lurus yaitu membandingkan tingkat produktivitas padi dengan jumlah tenaga kerja yang dicurahakan diperoleh nilai 17,18 yang berarti bahwa setiap 1 HKO menghasilkan $17,18 \mathrm{~kg} / \mathrm{HKO}$ padi. Apabila produksi padi dapat ditingkatkan sehingga memperoleh tingkat produktiviats padi yang lebih besar sehingga akan meningkatkan juga effisiensi tenaga kerjanya.

Dari segi indeks Produktivitas Tenaga Kerja diperoleh nilai Rp 84.046,71/HKO yang berarti bahwa setiap penambahan satu satuan tenaga kerja yang dicurahkan akan menambah peningkatan penerimaan sebesar Rp 84.046,71,. Dengan asumsi penambahan faktor produksi lainnya secara proporsional.Bila dibandingkan dengan tingkat upah yang berlaku di Desa Sungai Lurus rata-rata sebesar Rp 70.000,.

Tingkat efisiensi tenaga kerja dari segi luas lahan yaitu ratio antara luas lahan dengan jumlah tenaga kerja per hari diperoleh angka sebesar 0,825 yang artinya setiap $1 \mathrm{HKO}$ akan dapat mengerjakan lahan seluas 82,54 $\mathrm{m} 2$. Semakin kecil angka ini menunjukkan bahwa semakin tidak efisien, karena akan semakin banyak tenaga kerja yang dicurahkan pada luasan tertentul dan sebaliknya.

\section{KESIMPULAN DAN SARAN}

\section{Kesimpulan}

Berdasarkan hasil Penelitian bahwa Usahatani Padi di Lahan Kering dengan cara tanam jajar legowo di Desa Sungai Lurus,Kecamatan Sambung Makmur lahan 1,04 ha dengan tingkat produktivitas Padi Lahan Kering 2.081,44 kg/ha masih dibawah produktivitas standar nasional yaitu 4 ton/ha. Distribusi Tenaga Kerja Luar Keluarga ( TKLK) yaitu 88,73 \% dan Tenaga Kerja Dalam Keluarga ( TKDK) yaitu 11,27 \% dari total curahan tenaga kerja. Sedangkan untuk biaya tenaga kerja yaitu sebesar $75,85 \%$ terhadap total biaya usahatani yang merupakan kelompok biaya terbesar pada usahatani Padi.

Tingkat Efisiensi Tenaga Kerja dari Produktivitas Tenaga Kerja diperoleh nilai 
$17,18 \mathrm{~kg} / \mathrm{ha}$ dengan Indek Produktivitas Tenaga Kerja diperoleh nilai Rp 84.046,71, sedangkan dari segi luas lahan sebesar 82,54 $\mathrm{m} 2 / \mathrm{HKO}$.

\section{Saran}

Potensi Tenaga Kerja Produktif yang dimiliki Keluarga Petani sebagai modal dasar usahatani, dapat ditingkatkan lagi dalam penggunaannya dengan penamnbahan jam kerja per hari secara maksimal,sehingga efisiensi penggunaan tenaga kerja per luasan lahan dapat ditingkatkan.

\section{DAFTAR PUSTAKA}

AAK.1990.Budidaya Tanaman Padi Penerbit Kanisius. Yogyakarta

$\begin{array}{cr}\text { Afrida,2003.Ekonomi Sumber } & \text { Daya } \\ \text { Manusia.Ghalia.Jakarta } & \text { Dantes } \\ \text { Nyoman,2012.Metode } & \\ \text { Penelitian.Andi. Yogyakarta } & \end{array}$

Adi, Safruwardi, Hairin fajri, Hamdani, 2012. Analisis Finansial Usahatani Padi Varietas Unggul di Desa Guntung Ujung Kecamatan Gambut Kabupaten Banjar Kalimantan Selatan. Jurnal Agribisnis Perdesaan Volume 02 nomor 03 September 2012 hal 181-192

Alan Dwi Wibowo, 2016. Dinamika Ketersediaan Beras: Sebuah Studi Kasus Di Kalimantan Selatan.Jurnal Ziraa'ah Volume 41 Nomor 2 Juni 2016.ISSN Cetak 1412-1468 ISSN Elektronik 2355-3545

Dantes Nyoman, 2012. Metode Penelitian. Andi. Yogyakarta

Dinas Pertanian Tanaman Pangan, 2005. Sistem Pertanian dan Komoditi Unggulan pada Zona Ekologi di Kabupaten Banjar dan Kabupaten Tapin. DPTP. Kabupaten Banjar
Imran dan Syafrudin, 2005. Kajian Pengembangan Usahatani Padi dengan cara Tanam Jajar Legowo. Deptan. Jakarta

Kasim SA.,1995. Pengantar Ekonomi Produksi Pertanian.Fakultas Pertanian ULM.Penerbit Lambung Mangkurat.Banjarbaru

Masganti, Nurhayati, Nurmili Yuliani, 2017. Peningkatan Produktivitas Padi di Lahan Pasang Surut dengan Pupuk $P$ dan Kompos Jerami Padi. Jurnal Tanah dan Iklim vol 41 no 1 juli 2017: 17-24.ISSN 1410-7244.

Pahrudin., Maripul dan Philips Rido. 2004. Cara Tanam Padi Sistem Jajar Legowo mendukung Usahatani di Desa Bojong Kembar Sukabumi, Buletin Tehnik Pertanian

Prayitno,dkk. 2005. Produktivitas Empat Varietas padi gogo.Balai Pengkajian Teknologi Pertanian Yogyakarta

Priyono,2016. Metodologi Kuantitatif. Zifatama Publishing. Sidoarjo

Sugiyono,2013. Metodologi Penelitian Bisnis. Alfabeta. Bandung

Rahmi Zulhidiani. 2010. Produktivitas dan Susut Panen Padi Pada Lahan Lebak dan Irigasi Kabupaten Tabalong.Jurnal Chlorophyl Vol 6 no 1 Pebruari 2010.Faperta Univ Achmad Yani ISSN 1858-3954

Soekartawi, 2006. Analisis Usahatani. Penerbit Universitas Indonesia, Jakarta

Suparmi. 1986. Ekonomi Pertanian Karunika Jakarta Universitas Terbuka 
